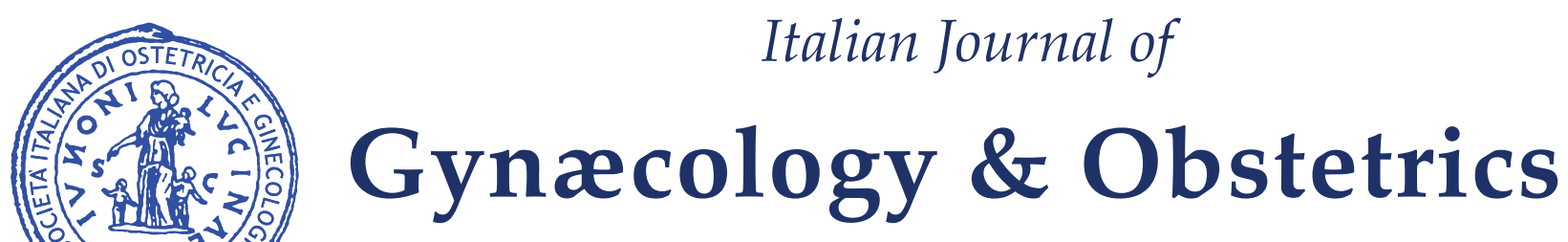

March 2021 - Vol. 33 - N. 1 - Quarterly - ISSN 2385 - 0868

\title{
Miscarriage: a social networks users' point of view
}

\author{
G. Troiano ${ }^{1}$, M. Cozzolino ${ }^{2,3,4}$ \\ ${ }^{1}$ ASST Melegnano e della Martesana, Italy \\ ${ }^{2}$ Department of Obstetrics, Gynaecology and Reproductive Sciences, Yale School of Medicine, New Haven, Connecticut, USA \\ ${ }^{3}$ IVIRMA, IVI Foundation, Valencia, Spain \\ ${ }^{4}$ Universidad Rey Juan Carlos, Móstoles, Madrid, Spain
}

\section{ABSTRACT}

Background. Every day several posts are published on social networks, however there are limited evidences about how miscarriage is perceived and disclosed by social network users. The aim of our review was, therefore, to collect studies focused on posts published in the main social networks (Instagram, Facebook, and Twitter) and regarding miscarriage, in order to give an overview of feelings and emotions perceived by social network users after a miscarriage.

Methods. In October-November 2020, we searched in the electronic database PubMed (MEDLINE), all the peer-reviewed journal articles published between January 2000 and November 2020. We considered eligible articles that reported clear data on 1) analyzed social network; 2) number of posts; 3) year of study; 4) interesting data about emotions perceived by social network users about miscarriage. Studies should be written in English, French, Spanish, Italian.

Results. Of the 32 found publications, 2 met the inclusion criteria: the studies have been conducted between 2017-2019 and analyzed posts published on Instagram and Twitter. Up to $50.6 \%$ (Twitter) and $16.2 \%$ (Instagram) women expressed grief and anger or annoyance in their posts but also conflicted emotions, regret, hope. In particular, the experience of recurrent pregnancy loss was perceived by women as stressing for their future pregnancies. Some women decided to show their miscarriage on the social network considering this action as an attempt to both seek support and to offer solidarity to others. Celebrity disclosures, published researches about miscarriage risk factors, and/or preventive methods for miscarriage generated a high number of discussions on Twitter.

\section{SOMMARIO}

Background. Diversi post vengono pubblicati ogni giorno sui social network, tuttavia ci sono prove limitate su come l'aborto spontaneo venga percepito e condiviso dagli utenti dei social network. Lo scopo della nostra review è stato, quindi, raccogliere studi incentrati sui post pubblicati nei principali social network (Instagram, Facebook e Twitter) riguardanti l'aborto spontaneo al fine di avere una panoramica delle sensazioni e delle emozioni percepite dagli utenti dei social network dopo un aborto spontaneo.

Metodi. Nel periodo ottobre-novembre 2020 abbiamo cercato nei database elettronici PubMed e MEDLINE tutti gli articoli di riviste peer-reviewed, pubblicati tra gennaio 2000 e novembre 2020. Abbiamo considerato idonei per la review gli articoli che riportavano dati chiari su: 1) social network analizzati; 2) numero di post; 3) anno dello studio; 4) dati interessanti riguardanti le emozioni percepite dagli utenti dei social network sull'aborto spontaneo. Abbiamo considerato solo gli studi in inglese, francese, spagnolo, italiano.

Risultati. Delle 32 pubblicazioni trovate, 2 soddisfacevano i criteri di inclusione: gli studi sono stati condotti nel periodo 2017-2019 e hanno analizzato i post pubblicati su Instagram e Twitter. Fino al 50.6\% (Twitter) e al 16.2\% (Instagram) delle donne hanno espresso dolore, rabbia o fastidio nei loro post, ma anche emozioni contrastanti, rimpianti, speranza. In particolare, l'esperienza di aborti ricorrenti è stata percepita dalle donne come stressante per le loro future gravidanze. Alcune donne hanno deciso di condividere la loro esperienza di aborto sui social network considerando questa azione come un tentativo sia di cercare sostegno sia di offrire solidarietà 
Conclusions. Miscarriage is usually perceived in a negative way on social networks, however, participation in online media could be useful because of the support usually given by others that experienced the same event. However, both studies that we included in the review didn't allow a complete overview about this interesting topic.

Corresponding Author: Gianmarco Troiano

E-mail: gianmarco-89@hotmail.it agli altri. Rivelazioni pubbliche da parte di celebrità, ricerche pubblicate sui fattori di rischio dell'aborto spontaneo e/ o metodi di prevenzione dell'aborto spontaneo hanno generato un numero elevato di discussioni su Twitter.

Conclusioni. L'aborto è solitamente percepito in modo negativo sui social network, tuttavia, la partecipazione nei social network potrebbe essere utile a causa del supporto solitamente fornito da altri che hanno vissuto lo stesso avvenimento. Tuttavia, entrambi gli studi che abbiamo incluso nella review non hanno consentito di ottenere una panoramica completa su questo interessante argomento.

Key words:

Miscarriage; social network; Instagram; Twitter; Facebook.

\section{Copyright 2021}

DOI: $10.36129 /$ jog.33.01.01

\section{INTRODUCTION}

In western societies, it has been estimated that approximately $20 \%$ of pregnancies end in spontaneous abortions (also known as miscarriages) within the first 22 weeks (1). Miscarriage has an important psychological impact on women's life (2). Women who experience miscarriage have an increased risk of depression and anxiety in the first month following Early Pregnancy Loss (EPL). Male partners also experience depression and anxiety, albeit at a generally lower level. There is also evidence of post-traumatic stress symptoms relating to $\operatorname{EPL}(2,3)$.

Women with recurrent miscarriage show psychological distress higher after abortion, it persists even after one year and with the worst outcomes in women from rural areas (4). A comparative study on quality of life among women with and without recurrent miscarriage using the 36-Item Short Form Survey (SF-36) and the Hospital Anxiety and Depression Scale (HADS) demonstrated that women with recurrent miscarriage reported extensive functional disability, and lower level of well-being compared to women without recurrent miscarriage (5). Results from another study indicated that anxiety, depression, and perinatal grief can persist for a long period after miscarriage (6). Also, more attention should be given to women in vulnerable situations, such as immigrant women, women with low socioeconomic status, or childless women. Beyond those personal and contextual factors, the quality of the conjugal relationship and the level of satisfaction with health care appeared to be important protective factors against mental health problems after a spontaneous abortion (6). In couples with recurrent pregnancy loss (RPL), medical professionals need to take a holistic and couple-focused approach in their treatment including attention to the psychological impact and cumulative effect of the multiple RPL on the couple (7). Research also shows that women with pregnancy loss are dissatisfied with the medical care they receive and wish for more information, empathy, psychological support and follow-up, and to know the cause of the pregnancy loss (8). Social networks can play a crucial role in helping and encouraging individuals after pregnancy loss by providing a positive support system that helps in lessening feelings of grief and loss (9). On the other side, previous studies evidenced a "dark side" of some social networks, especially those based mostly on photos/videos, demonstrating a significant relationship between more social network activity based on sharing, seeing, and commenting on photographs and body image impairment and problems in regulating emotions (10). However, the role of these image-based social media platforms in health communication and public health remains underexplored $(11,12)$.

This narrative review tries to provide a descriptive overview of miscarriage as perceived and described via posts published on Instagram, Facebook, and Twitter. We summarize the research literature up 
to November 2020. The scope of this review is a priori limited to Instagram, Facebook and Twitter because considered the most used social networks $(13,14)$. The aim of our review was, therefore, to collect studies focused on posts published in the main social networks (Instagram, Facebook, and Twitter) regarding miscarriage to give an overview of feelings and emotions perceived by social network users after a miscarriage.

\section{MATERIALS AND METHODS}

\section{Search strategy}

In October-November 2020, we searched in the electronic database PubMed (MEDLINE), all the peer-reviewed journal articles published between January 2000 and November 2020. This narrative review aimed to identify and describe the messages presented in posts published in the main social media (Twitter, Instagram, and Facebook) about miscarriage to identify future directions for research, surveillance, and regulation. The following combination of $\mathrm{MeSH}$ terms was used "Social Network AND Miscarriage", "Facebook AND Miscarriage", "Twitter AND Miscarriage", "Instagram AND Miscarriage" OR Pregnancy Loss, Spontaneous abortion.

\section{Inclusion criteria}

We considered eligible articles (original articles, but also letters to the editor if containing original data) that reported clear data on 1) analyzed social network; 2) number of posts; 3) year of study; 4) interesting data about emotions perceived by social network users about miscarriage. We considered eligible studies written in English, French, Spanish, Italian.

The studies we decided to include were descriptive studies in which authors extracted posts containing phrases or hashtags related to miscarriage, and then analyzed them using especially a qualitative method.

\section{Study selection and data extraction}

Studies were selected in a 2-stage process. Titles and abstracts were screened independently by two authors (MC, GT). The same authors independently assessed studies for inclusion and extracted data. A manual search of references within the included

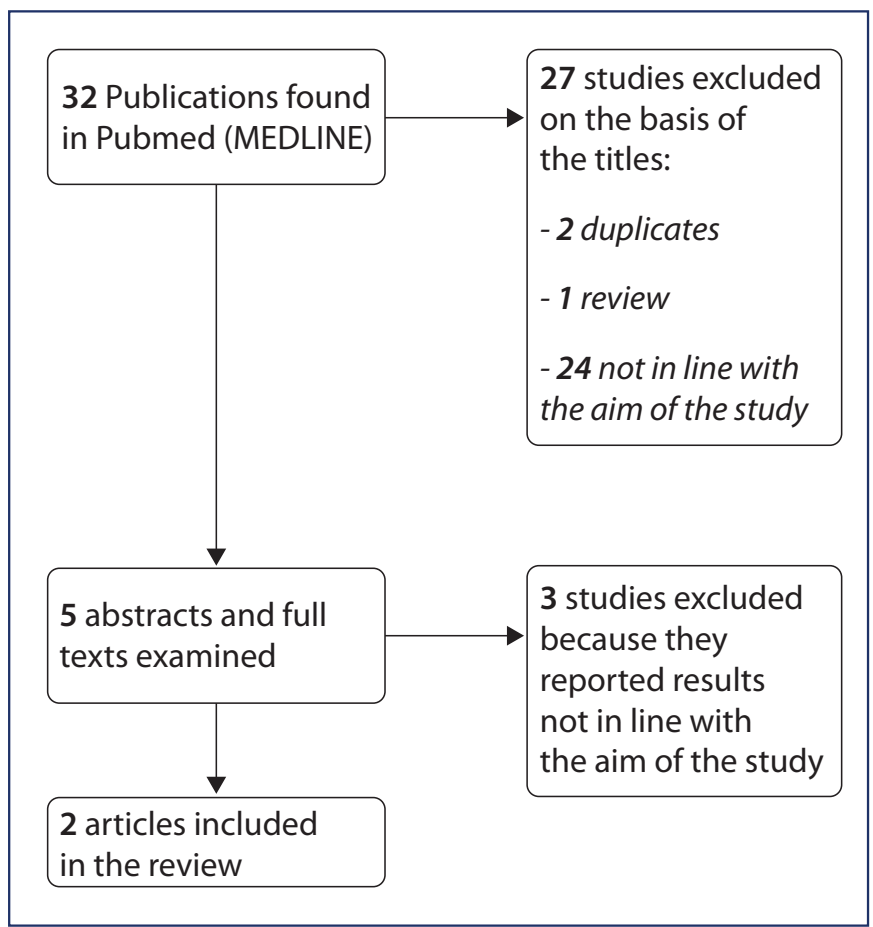

Figure 1. Flow diagram for identifying studies to be included in the review.

studies was also performed to avoid any missing relevant data. Any disagreement concerning the extracted data was resolved by consensus. Selected articles were read in full by MC and GT.

\section{RESULTS}

The literature search yielded 32 publications. The titles of these manuscripts were screened, resulting in 5 studies considered potentially eligible to be included in the review ( 2 articles were excluded because they were duplicates, 1 was a review, 24 were not in line with the aim of the study). 3 studies were excluded after an examination of the abstracts and the full texts (they reported results not in line with the aim of the study). Finally, after this exclusion, we identified 2 manuscripts $(15,16)$ (figure 1).

\section{Main characteristics of the studies}

The principal results of our review are shown in table I. The only two studies included in our review have been published in 2019 and 2020 and have been conducted between 2017-2019. In these studies, authors collected and analyzed posts retrieved from 2 social networks: Instagram and Twitter (respectively 200 posts and 291443 tweets). No article about Facebook has met the inclusion criteria. 
Table I. Selected characteristics of the studies included in our review $(n / r=$ not reported; * $=$ year of publication; $1=$ number of users from whom the posts have been analyzed; 2 = datum calculated on 7282 tweets from 5079 users).

\begin{tabular}{|c|c|c|c|c|c|c|}
\hline $\begin{array}{l}\text { AUTHOR, } \\
\text { YEAR* }\end{array}$ & $\begin{array}{l}\text { SOCIAL } \\
\text { NETWORK }\end{array}$ & YEAR & $\begin{array}{l}\text { STUDY } \\
\text { DESIGN }\end{array}$ & POSTS (N) & USERS (1) & MAIN FINDINGS \\
\hline $\begin{array}{l}\text { Cesare, } \\
2019\end{array}$ & Twitter & $2017-2018$ & $\mathrm{n} / \mathrm{r}$ & 291443 & 138658 & $\begin{array}{l}\text { The major topics of discussion were: Michelle Obama ( } 8.4 \%) \text {, } \\
\text { Celebrity }(23.0 \%) \text {, Preterm birth (10.9\%), Politics (17.6\%), Loss and } \\
\text { Anxiety }(10.1 \%) \text {, Ectopic pregnancy }(7.5 \%) \text {, Healthcare }(10.7 \%) \text {, } \\
\text { Influenza Vaccine ( } 11.7 \%) \text {. } \\
\text { - Increase of discussions about miscarriage during celebrity } \\
\text { disclosures, research studies on risk factors and preventive methods } \\
\text { for miscarriage. } \\
\text { - Michelle Obama's disclosures generated } 3051 \text { tweets ( } 3.6 \text { times the } \\
\text { magnitude of the highest weekly average). } \\
\cdot 50.6 \% \text { and } 16.2 \% \text { expressed grief and anger or annoyance } \\
\text { respectively (2). } \\
\cdot 0.6 \% \text { expressed relief because not ready to be parent. } \\
\cdot 14.2 \% \text { of tweets were neutral. } \\
\text { - } 4.7 \% \text { of tweets blamed their body, behavior of circumstances for } \\
\text { their miscarriage. }\end{array}$ \\
\hline $\begin{array}{l}\text { Mercier, } \\
2020\end{array}$ & Instagram & 2019 & Cross sectional & 200 & $n / r$ & $\begin{array}{l}\text { - A lot of posts reported a rich description of medical and physical } \\
\text { experience of miscarriage. } \\
\text { - A lot of posts reported a description of lack of fetal cardiac activity. } \\
\cdot 2 \text { posts described the experience of miscarriage on an airplane and } \\
\text { in a bathroom. } \\
\text { - Miscarriage is often seen as a milestone. } \\
\text { - A lot of posts are a request of support. } \\
\text { - A lot of posts reported fear or conflicted feelings about sharing } \\
\text { one's miscarriage. } \\
\text { - Most experienced feelings: grief, conflicted emotions, anger, } \\
\text { regret, hope. } \\
\text { - Recurrent pregnancy loss has effects on one's identity, and creates } \\
\text { worry and stress about a future pregnancy. } \\
\text { - Some posts reported the term "Rainbow baby" used to describe a } \\
\text { baby born after a miscarriage. } \\
\text { - Remembrance of the miscarriage is seen as a common element of } \\
\text { coping. }\end{array}$ \\
\hline
\end{tabular}

\section{Miscarriage: Social networks users' point of view}

Our analysis has shown that negative feelings are often strictly connected to miscarriage and emerge also in social networks: up to $50.6 \%$ (Twitter) and $16.2 \%$ (Instagram) women expressed grief and anger or annoyance in their posts but also conflicted emotions, regret, hope. In some cases, women blamed their body, behavior of circumstances for their miscarriage. In particular, the experience of recurrent pregnancy loss was perceived by women as stressing for their future pregnancies. Only a small percentage $(0.6 \%)$ of women expressed relief because declared not to be ready to be parents. Some women decided to show their miscarriage on the social network considering this action as an attempt to both seek support and to offer solidarity to others. An important public figure, i.e., Michelle Obama, publicly talked about her experience of miscarriage; this news increased in an important way the average number of tweets. Beyond celebrity disclosures, a general increase of discussions on Twitter has also been observed in occasion of published researches about miscarriage risk factors, and/or preventive methods for miscarriage.

\section{DISCUSSION}

Several posts are published every day on social networks, however there are limited evidences about how miscarriage is perceived and disclosed by social network users. Our review tried to analyzed the published articles on this topic in order to have an overview.

Our results, although limited to two social networks (Instagram and Twitter), show that the general attitude related to miscarriage and disclosure on social networks post is generally negative. In this context, previous studies suggested that women (especially those with recurrent spontaneous abortions - RSA) should receive psychological counseling to handle the distress they experience. Thus, the psychological management of distress in 
women with miscarriage must be included in the treatment of RSA (4). In fact, compassionate care, informational guidance, and timed follow-up positively impact patient outcomes (17).

Education of healthcare professionals is important to address misconceptions about miscarriage, increase confidence in providing support, and promote effective care. Women and families experiencing miscarriage need privacy and timeliness in care. Interventions such as funded midwifery loss care or a routine telephone follow-up call could improve access to care and help healthcare professionals ensure that families obtain the type and amount of support that they need $(1,18)$.

On Instagram, the experience of recurrent pregnancy loss was perceived by women as stressing for their future pregnancies. It is well described in the literature that women with recurrent miscarriage tend to have a lower level of well-being compared to women without recurrent miscarriage, and an appropriate treatment is essential for their psychological distress (5). Our review highlighted a general increase of discussions in occasion of public disclosures, published researches about miscarriage risk factors, and / or preventive methods for miscarriage. Michelle Obama revealed she suffered a miscarriage 20 years ago and used IVF to help conceive her daughters Sasha and Malia (19). The public disclosure of a health problem from a public figure is an extensively studied phenomenon. For example, Angelina Jolie, Jade Goody, Kylie Minogue, Nancy Reagan, and Steve Jobs were studied for their cancers (breast, cervical, pancreatic, etc.) (20-22). Lots of studies highlighted a clear effect of celebrity medical news on the population (for example the openness to consider genetic testing as an early detection tool for women with a family history of breast and / or ovarian cancer) (23).

Although a very high percentage of women expressed grief, anger, and other negative feelings after a miscarriage, some women decided to show their miscarriage on the social network considering this action as an attempt to both seek support and to offer solidarity to others. Many individuals ex- pressed their solidarity on social networks and sympathized with persons affected by some pathologies (24). It is also evident that people affected by some pathologies interact with one another via social networks. As social media become frequently used as a source of medical information, professionals should be aware of the content available and consider using them as a means to provide health education (24). As described by other authors, for example, one of the disadvantages of participating in some forums was becoming emotionally affected by other members' negative experiences. Further, some participants described that some information given in the forums were inaccurate. Forum members can have limited knowledge of the medical history of the other members and therefore the given advice and information may not be adequate in every case (25).

Both studies that we included in the review didn't allow a complete overview about this interesting topic so we encourage other colleagues to perform further studies - in other countries, or including a higher number of posts or analyzing other social networks such as Facebook - in order to have a better knowledge about it.

\section{CONCLUSIONS}

Social networks are interesting tools, well studied for their influence on an extensive number of people (26). Miscarriage is usually perceived in a negative way on social networks, however, participation in online media could be useful because of the support usually given by others that experienced the same event. Solidarity, receiving and giving support are certainly positive elements, however, they should be integrated by an emotional (and professional) support given by healthcare workers.

\section{CONFLICT OF INTERESTS}

The authors declare that they have no conflict of interests. 


\section{REFERENCES}

1. Engel J, Rempel L. Health Professionals' Practices and Attitudes About Miscarriage. MCN Am J Matern Child Nurs 2016;41(1):51-7.

2. Farren J, Mitchell-Jones N, Verbakel JY, Timmerman D, Jalmbrant $M$, Bourne T. The psychological impact of early pregnancy loss. Hum Reprod Update 2018;24(6):731-49.

3. Cozzolino M, Troiano G, Coccia ME. Spontaneous pregnancy versus assisted reproductive technologies: implications on maternal mental health. Women Health 2021;61(3):303-12.

4. Adib-Rad H, Basirat Z, Faramarzi M, Mostafazadeh A, Bijani A. Psychological distress in women with recurrent spontaneous abortion: A case-control study. Turk J Obstet Gynecol 2019;16(3):151-7.

5. Tavoli Z, Mohammadi M, Tavoli A, et al. Quality of life and psychological distress in women with recurrent miscarriage: a comparative study. Health Qual Life Outcomes 2018;16(1):150.

6. DeMontigny F, Verdon C, Meunier S, Gervais C, Coté I. Protective and risk factors for women's mental health after a spontaneous abortion. Rev Lat Am Enfermagem 2020;28:e3350.

7. Koert E, Malling GMH, Sylvest R, et al. Recurrent pregnancy loss: couples' perspectives on their need for treatment, support and follow up. Hum Reprod 2019;34(2):291-6.

8. Simmons RK, Singh G, Maconochie N, Doyle P, Green J. Experience of miscarriage in the UK: qualitative findings from the National Women's Health Study. Soc Sci Med 2006;63(7):1934-46.

9. Bellhouse C, Temple-Smith MJ, Bilardi JE. “It's just one of those things people don't seem to talk about..." women's experiences of social support following miscarriage: a qualitative study. BMC Womens Health 2018;18(1):176.

10. Senín-Calderón C, Perona-Garcelán S, Rodríguez-Testal JF. The dark side of Instagram: Predictor model of dysmorphic concerns. Int J Clin Health Psychol 2020;20(3):253-61.

11. Fung IC, Blankenship EB, Ahweyevu JO, et al. Public Health Implications of Image-Based Social Media: A Systematic Review of Instagram, Pinterest, Tumblr, and Flickr. Perm J 2020;24:18.307.

12. Nante N, Troiano G. Emoji: What does the scientific literature say about them? - A new way to communicate in the 21th century. J Hum Behav Soc Environ 2018,28(4):528-33.
13. Jeri-Yabar A, Sanchez-Carbonel A, Tito K, et al. Association between social media use (Twitter, Instagram, Facebook) and depressive symptoms: Are Twitter users at higher risk? Int J Soc Psychiatry 2019;65(1):14-9.

14. Struck JP, Siegel F, Kramer MW, et al. Substantial utilization of Facebook, Twitter, YouTube, and Instagram in the prostate cancer community. World J Urol 2018;36(8):1241-6.

15. Cesare N, Oladeji O, Ferryman K, et al. Discussions of miscarriage and preterm births on Twitter. Paediatr Perinat Epidemiol 2020;34(5):544-52.

16. Mercier RJ, Senter K, Webster R, Henderson Riley A. Instagram Users' Experiences of Miscarriage. Obstet Gynecol 2020;135(1):166-73.

17. Rich D. Psychological Impact of Pregnancy Loss: Best Practice for Obstetric Providers. Clin Obstet Gynecol 2018;61(3):628-36.

18. Zegers-Hochschild F, Adamson GD, Dyer S, et al. The International Glossary on Infertility and Fertility Care, 2017. Fertil Steril 2017;108(3):393406.

19. Perrigo B. Michelle Obama Reveals She Suffered a Miscarriage 20 Years Ago and Used IVF to Help Conceive Sasha and Malia. 2019. Available at: https://time.com/5450215/michelle-obama-ivf-miscarriage/. Accessed: $04 / 11 / 2020$.

20. Noar SM, Willoughby JF, Myrick JG, Brown J. Public figure announcements about cancer and opportunities for cancer communication: a review and research agenda. Health Commun 2014;29(5):445-61.

21. Troiano G, Nante N, Cozzolino M. The Angelina Jolie effect - Impact on breast and ovarian cancer prevention A systematic review of effects after the public announcement in May 2013. Health Educ J 2017;76(6):707-15.

22. Bocci G, Troiano G, Messina G, Nante N, Civitelli S. Factors that could influence women's participation in colorectal cancer screening: an Italian study. Ann Ig 2017;29(2):151-60.

23. Al-Hussaini M, Ammar K, Kasasbeh N, Sultan H, Al-Omari A. Global celebrities' effect on health awareness among Jordanians: A study using the case of Angelina Jolie. J Genet Couns 2019;28(5):1021-8.

24. Sycinska-Dziarnowska M, Stepien P, Janiszewska-Olszowska J, Grocholewicz K, Jedlinski M, Grassi R, Mazur M. Analysis of Instagram ${ }^{\circledR}$ Posts Referring to Cleft Lip. Int J Environ Res Public Health 2020;17(20):7404. 
25. Sormunen T, Karlgren K, Aanesen A, Fossum B, Westerbotn $\mathrm{M}$. The role of social media for persons affected by infertility. BMC Womens Health 2020;20(1):112.
26. Vicari S. Twitter and Non-Elites: Interpreting Power Dynamics in the Life Story of the (\#)BRCA Twitter Stream. Soc Media Soc 2017;3(3):205630511773322. 